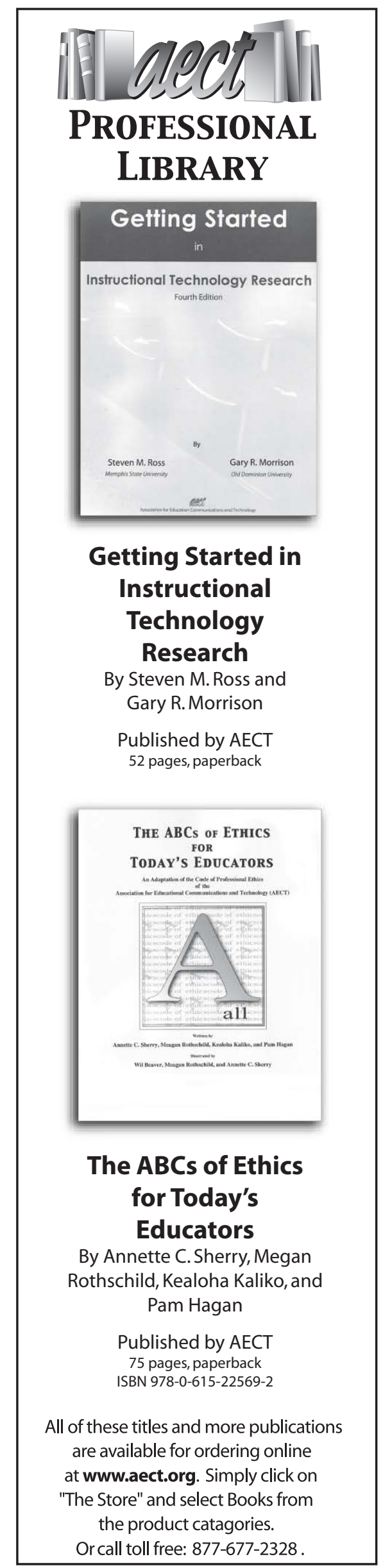

\title{
Welcoming Change
}

\author{
By Marcus D. Childress, \\ AECT President
}

B e ready, and welcome it when it is your turn to experience change, for there is nothing like it to heighten your sensibilities and elevate your mind. - Marcus Aurelius (Hicks \& Hicks, 2002).

Change is upon us. AECT has a new president, AECT divisions and affiliates have new leadership, and soon we will be approaching a new calendar year. As your new AECT president, I am excited by the many new challenges that our organization will likely encounter during my presidency. Thanks to the leadership of past-president Ana Donaldson, our executive committee, board of directors, division/affiliate leaders, Executive Director Phil Harris and the AECT staff, our organization is vibrant and healthy.

\section{Membership Growth}

My presidential candidate statement and goals (what now seems like a long, long time ago) focused on membership growth and increased visibility/influence. I feel strongly that growth of AECT's membership is achievable through closer relationships with state and international affiliates. The global appeal of our organization positions us to address the professional needs of more individuals. I challenge AECT members to reach out to their colleagues and students by showing them the advantages of AECT membership and hopefully encouraging them to join our organization. While a yearly increase of 2-3\% might be acceptable for an organization such as ours, I am aiming for a double-digit percentage increase in membership for the coming year.

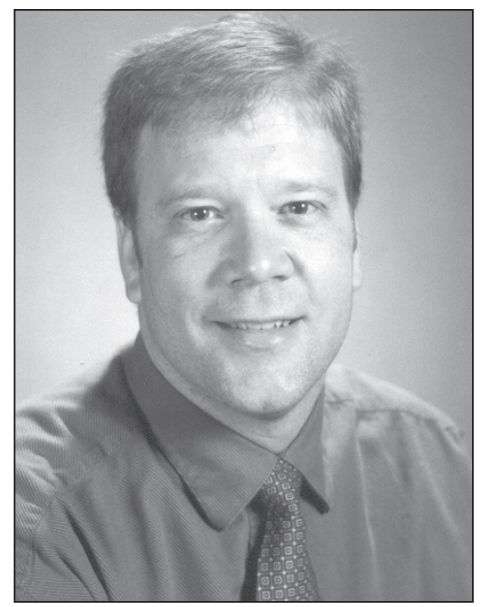

Marcus D. Childress

\section{Visibility/Influence}

As one of only a few associations related to instructional design/education technology/media that includes both practitioners and researchers, AECT is positioned to inform practices and policies at both a national and global level. Member involvement in national and international panels, publication of whitepapers and press releases can increase visibility of our organization. I challenge AECT members to dedicate some time and energy (and ink) toward increasing your visibility and influence upon policies and opinions that affect us. Increasing the visibility of our organization will also pay dividends in terms of membership growth. I hope that, in addition to including your school/professional affiliation on your publications, presentations and blog posts, you will consider adding one more line that indicates your affiliation with AECT.

As Marcus Aurelius (after whom I was named, by the way) advised, I look forward to welcoming change and working with you to elevate our organization to new and greater heights.

\section{Reference}

\footnotetext{
Hicks, C. S., \& Hicks, D. V. (2002). The emperor's handbook: A new translation of the meditations. New York: Scribner.
} 